Key messages

- The median survival of patients with metastatic non-small cell lung cancer is improved by about 3 months with the addition of chemotherapy

- Lung cancer patients who had had chemotherapy were interviewed in this study to learn about their treatment preferences with a range of survival benefits

- Several patients would choose chemotherapy for a survival benefit of as little as 1 week, while others would not choose chemotherapy even when offered a survival benefit of 24 months

- Most patients would not choose chemotherapy for its likely survival benefit of 3 months, but would if it improved quality of life

- Some patients with lung cancer may not be getting the treatment they would choose were they fully informed

requires that they are fully aware of the merits of chemotherapy. Our results suggest that some patients may not be getting what they want.

We thank Amanda Budak for helping with the survey, Robert Nease for helping with its design, Gary Thomas, George Geils, Robert Wall, and David Ellison for the use of their surgeries, and the patients. The views expressed in this paper are not necessarily those of the Department of Veterans Affairs or the United States government.

Contributors: GS and RP conceived and designed the study, conducted the interviews, and wrote the paper. HGW designed the study, analysed the data, and wrote the paper; he will act as guarantor for the paper.

1 Parker S, Tong T, Bolden S, Wingo P. Cancer statistics, 1997. CA Cancer J Clin 1997; 47:5-27.

2 Ginsberg R, Kris M, Armstrong J. Cancer of the lung: non-small cell lung cancer. In: DeVita JV, Hellman S, Rosenberg S, eds. Cancer:principles and practice of oncology. Philadelphia: JB Lippincott, 1993:673-723.

3 Grilli R, Oxman A, Julian J. Chemotherapy for advanced non-small cell lung cancer: how much benefit is enough? J Clin Oncol 1993;11:1866-72.

4 Marino P, Pampallona S, Preatoni A, Cantoni A, Invernizzi F. Chemotherapy vs supportive care in advanced non-small cell lung cancer: results of a meta-analysis of the literature. Chest 1994;106:861-5.

5 Souquet PJ, Chauvin F, Boissel JP, Cellerino R, Cormier Y, Ganz PA, et al Polychemotherapy in advanced non-small cell lung cancer: a meta-analysis. Lancet 1993;342:19-21.

6 Richards MA, Ramirez AJ, Degner LF, Fallowfield LJ, Maher EJ, Neuberger J. Offering choice of treatment to patients with cancer: a review based on symposium held at the 10th annual conference of the British Psychosocial Oncology Group, December 1993. Eur J Cancer 1995;31A:112-6.

7 Yellen S, Cella D, Leslie W. Age and clinical decision-making in oncology patients. J Natl Cancer Inst 1994;86:1766-70.

8 McQuellon RP, Muss HB, Hoffman SL, Russell G, Craven B, Yellen SB Patient preferences for treatment of metastatic breast cancer: a study of women with early breast cancer. J Clin Oncol 1995;13:858-68.

9 Sox H, Blatt M, Higgins M, Marton K. Medical decision making. Boston: Butterworths, 1988 .

10 Read J, Quinn R, Berwick D, Finebergh HF, Weinstein M. Preferences for health outcomes. Comparison of assessment methods. Med Decis Making 1984;4:315-29.

11 Nord E. Methods for quality adjustment of life years. Med Decis Making 1992;34:559-69.

12 Stiggelbout AM, Kiebert GM, Kievit J, Leer JW, Stoter G, de Haes JC. Utility assessment in cancer patients: adjustment of time tradeoff scores for the utility of life years and comparison with standard gamble scores. Med Decis Making 1994;14:82-90.

13 Kassirer J. Incorporating patients' preferences into medical decisions. $N$ Engl J Med 1994:330:1895-6.

14 McNeil B, Pauker S, Sox H, Tversky A. On the elicitation of preferences for alternative therapies. N Engl J Med 1982;306:1259-62.

15 Slevin ML, Stubbs L, Plant HJ, Wilson P, Gregory W, Armes PJ, et al. Attitudes to chemotherapy; comparing views of patients with cancer with those of doctors, nurses, and general public. BMJ 1990;300:1458-60

16 Brundage MD, Davidson JR, Mackillop WJ. Trading treatment toxicity for survival in locally advanced non-small cell lung cancer. J Clin Oncol 1997;15:330-40.

(Accepted 2 June 1998)

\title{
Working hours as a risk factor for acute myocardial infarction in Japan: case-control study
}

Shigeru Sokejima, Sadanobu Kagamimori

\author{
Abstract \\ Objective: To clarify the extent to which working \\ hours affect the risk of acute myocardial infarction, \\ independent of established risk factors and \\ occupational conditions. \\ Design: Case-control study. \\ Setting: University and general hospitals and routine \\ medical examinations at workplaces in Japan. \\ Subjects: Cases were 195 men aged 30-69 years \\ admitted to hospital with acute myocardial infarction \\ during 1990-3. Controls were 331 men matched at \\ group level for age and occupation who were judged \\ to be free of coronary heart diseases at routine \\ medical examinations in the workplace. \\ Main outcome measures: Odds ratios for myocardial \\ infarction in relation to previous mean daily working \\ hours in a month and changes in mean working \\ hours during previous year. \\ Results: Compared with men with mean working \\ hours of $>7-9$ hours, the odds ratio of acute \\ myocardial infarction (adjusted for age and
}

occupation) for men with working hours of $>11$

hours was 2.44 (95\% confidence interval 1.26 to 4.73$)$

and for men with working hours of $\leqslant 7$ hours was 3.07 (1.77 to 5.32). Compared with men who experienced an increase of $\leqslant 1$ hour in mean working hours, the adjusted odds ratio of myocardial infarction for men who experienced an increase of $>3$ hours was 2.53 (1.34 to 4.77 ). No appreciable change was observed when odds ratios were adjusted for established and psychosocial risk factors for myocardial infarction.

Conclusion: There was a $\mathrm{U}$ shaped relation between the mean working hours and the risk of acute myocardial infarction. There also seemed to be a trend for the risk of infarction to increase with greater increases in mean working hours.

\section{Introduction}

The occurrence of disease that may relate to working hours is an important consideration in Japan, where working hours have been unusually long. ${ }^{1}$ Uehata has 
reported that two thirds of 203 victims of sudden death who were under occupational stresses were working more than 60 hours a week. ${ }^{2}$ No analytical studies, however, have examined whether long working hours and changes in working hours influence the occurrence of such cases, including those of acute myocardial infarction.

Compared with other countries, Japan has low levels of morbidity and mortality from acute myocardial infarction. ${ }^{3-5}$ Immigration studies have suggested that established risk factors cannot sufficiently explain the marked differences. ${ }^{6}$ In addition, the age adjusted mortality of acute myocardial infarction has decreased in the past two decades in Japan, while the serum lipid profile has deteriorated..$^{7-9}$ This finding might correlate with changes in working hours during this period. ${ }^{1}$ Psychosocial aspects of working conditions that are thought to contribute to acute myocardial infarction in Europe and America have not been found to increase the risk of infarction in Japanese populations. ${ }^{1011}$ Working hours per se, a simple and universal condition across all workers, might independently contribute to acute myocardial infarction.

In Japan the lifetime employment system has been generally adopted for most occupations. In this system there is a tendency toward short term fluctuations in work demand that are adjusted for largely by monthly changes in the working hours of each worker. The sensitivity of working hours to boom and recession is thus much higher in Japan than in Britain and the United States. Because there is a definite seasonality in economic activity, working hours also change during the year.

The general aim of this study was to clarify the extent to which working hours might affect the risk of acute myocardial infarction. We examined the hypothesis that number of working hours and changes in working hours are involved in the onset of myocardial infarction independently of established risk factors and psychosocial factors relating to occupation and employment grade that are suspected to increase the risk of infarction. ${ }^{12-14}$

\section{Subjects and methods}

In a pilot study, in which we recruited 125 cases with acute myocardial infarction and 125 controls individually matched for age and occupation, we found a significant relation between working hours and risk of myocardial infarction.

In the present study, we recruited 199 male patients who had been admitted to three university hospitals and one general hospital between November 1990 and November 1993 for a first attack of acute myocardial infarction. The diagnosis was confirmed and was defined as typical chest pain lasting at least 20 minutes, an electrocardiogram showing ST elevation of at least $2 \mathrm{~mm}$ in two or more contiguous leads with subsequent evolution of the typical electrocardiographic changes, and diagnostic enzyme changes. We had to remove two patients, classified as agricultural workers, from the study because we found no control subjects for that occupation. In addition, we removed one patient because we could find no control with matching age. Another subject was found to have a history of cerebrovascular stroke and was therefore also removed from the study. Consequently, 195 patients $(98 \%)$ were included in the study.

For controls, we recruited 339 male workers free of coronary heart disease who were matched to the cases for age (within three years) and occupation. These men were selected at routine medical examinations conducted at their workplace. In Japan, under the Medical Service Law, each worker receives an annual medical examination, including an electrocardiogram and measurement of blood pressure, serum total cholesterol concentration, urinary glucose concentration, body weight, and height. Therefore, these men were well informed of their health status, including risk factors for cardiovascular diseases. We used their occupational categories, defined in the Japanese census of 1990 (table 1), for matching. ${ }^{15}$ We sent these men questionnaires (see below) and obtained 332 complete responses. One of these 332 subjects was found to have a history of angina pectoris and was therefore removed from the study. Consequently, 331 subjects (98\%) were included in the control group.

\section{Questionnaire}

All the subjects completed a self administered questionnaire about their working hours and psychosocial working conditions, cases being given the questionnaire before their discharge from hospital. The cases were asked for their mean working hours per day, excluding holidays and days of rest, for each of the two months preceding their acute myocardial infarction and for each of the months with the shortest and longest mean daily working hours for the year before their infarction. The controls were asked about working hours for the months before their recruitment to the study. In Japan each worker is given a table of salary details every month and is informed of the number of days he or she is going to work, including the overtime hours. It was therefore easy for the subjects to recall the number of hours they had worked in earlier months. From these results we calculated the degree to which mean working hours had changed.

The subjects were asked about psychosocial conditions in the month before their infarction (or recruitment to the study). We asked for the proportion of their working hours that were spent in sedentary work. ${ }^{16}{ }^{17}$ To assess the subjects' emotional state, ${ }^{18}$ we used the "burnout measure" developed by Pines (presented at the National Conference on Burnout in the Human Services, Philadelphia, November 1981). This measure, which has been well validated in Japan, is composed of 21 questions about the frequency of positive and negative feelings. We used the score derived from the responses to define burnout and borderline states.

We recorded established risk factors for acute myocardial infarction: history of hypertension, hypercholesterolaemia, diabetes mellitus (including impaired glucose tolerance), and smoking habits. These were assessed during the cases' hospitalisation or during the controls' medical check up in their workplace. ${ }^{14}$ To calculate body mass index, ${ }^{19}$ we also recorded body weight and height, which were measured at the hospital or at the most recent medical check up. 


\section{Statistical analysis}

We assessed associations between premorbid variables and the risk of acute myocardial infarction by conditional logistic regression, ${ }^{20}$ which was performed by the PHREG procedure in the SAS statistical package. ${ }^{21}$ For this analysis, we used occupational categories (see table 1) to separate the subjects into matched sets. Age was used as a continuous variable for adjustment because it was matched within three years between cases and controls. Established risk factors for myocardial infarction and psychosocial working conditions were assessed as categorical indicator variables (table 1). We used analyses of variance and covariance to compare the mean working hours (adjusted for age and occupation), and the changes in working hours during the months before myocardial infarction, of the case and control groups. Conditional logistic regression analysis was used to assess crude associations between mean working hours and the risk of acute myocardial infarction.

We then grouped the data on mean working hours, and changes in hours, into four categories (see table 3). Further conditional logistic regression analysis was used to examine whether crude associations were confounded by established risk factors for myocardial infarction (hypertension, hypercholesterolaemia, diabetes, body mass index, and smoking habits) or psychosocial aspects of work (amount of sedentary work and burnout index). Variables were selected for inclusion in the models on the basis of biological and psychosocial plausibility and evidence of confounding. The SAS statistical package was used for the analysis.

\section{Results}

\section{Background characteristics}

The mean ages of the 195 cases and 331 controls were 55.50 years (SD 8.40, range $30-69$ ) and 54.41 years $(8.26,31-72)$ respectively. Table 1 shows their background characteristics. Each of the established risk factors for acute myocardial infarction was associated with an increased risk of infarction, while the psychosocial aspects of working conditions were not associated.

\section{Working hours}

Table 2 shows the mean working hours of the study groups during the months before infarction. The results for the two groups were not significantly different, except that the shortest mean daily working hours for a single month was significantly less for the cases. The two groups had significantly different changes in mean daily working hours between two months, except for the change between the month before the infarction and the month with the longest mean working hours.

Table 3 shows the results of conditional logistic regression analyses after we grouped the data on working hours into four categories. For the month before the myocardial infarction, both a long mean working day ( $>11$ hours) and a short working day $(\leqslant 7$ hours) were associated with a significantly increased risk of infarction compared with working $>7-9$ hours (odds ratios 2.44 (95\% confidence interval 1.26 to 4.73 ) and 3.07 (1.77 to 5.32) respectively) (see figure). Adjustment for established risk factors and psychoso-
Table 1 Background characteristics of 195 Japanese men with acute myocardial infarction and 331 controls matched for age and occupation, and odds ratios for infarction in relation to established risk factors and psychosocial conditions

\begin{tabular}{|c|c|c|c|}
\hline & \multicolumn{2}{|c|}{ No $(\%)$ of subjects } & \multirow[b]{2}{*}{$\begin{array}{c}\text { Odds ratio* } \\
(95 \% \mathrm{CI})\end{array}$} \\
\hline & $\begin{array}{c}\text { Cases } \\
(n=195)\end{array}$ & $\begin{array}{l}\text { Controls } \\
(n=331)\end{array}$ & \\
\hline \multicolumn{4}{|l|}{ Occupation† } \\
\hline Managers and officials & $100(51)$ & $169(51)$ & NA \\
\hline Professional and technical & $29(15)$ & $46(14)$ & NA \\
\hline Clerical and related & $23(12)$ & $31(9)$ & NA \\
\hline Sales & $9(5)$ & $10(3)$ & NA \\
\hline Crafts, production process, construction, and labouring & $23(12)$ & $61(18)$ & NA \\
\hline Transport and communications & $5(3)$ & $9(3)$ & NA \\
\hline Services & $5(3)$ & $3(1)$ & NA \\
\hline Emergency services & $1(1)$ & $2(1)$ & NA \\
\hline \multicolumn{4}{|l|}{ Biomedical history } \\
\hline Hypertension & $97(50)$ & $71(21)$ & 3.64 (2.45 to 5.42$)$ \\
\hline Hypercholesterolaemia & $90(46)$ & $71(21)$ & 3.16 (2.14 to 4.66$)$ \\
\hline Diabetes & $50(26)$ & $40(12)$ & 2.38 (1.50 to 3.79 ) \\
\hline \multicolumn{4}{|l|}{ Smokers: } \\
\hline Never & $27(14)$ & $78(24)$ & 1.00 \\
\hline Former & $47(24)$ & $98(30)$ & $1.36(0.77$ to 2.40$)$ \\
\hline Current & $121(62)$ & $155(47)$ & 2.34 (1.41 to 3.87 ) \\
\hline \multicolumn{4}{|l|}{ Body mass index $\left(\mathrm{kg} / \mathrm{m}^{2}\right)$ : } \\
\hline$\leqslant 19.7$ & $9(5)$ & $31(9)$ & 0.64 (0.29 to 1.42$)$ \\
\hline $19.8-24.2$ & $98(50)$ & $185(56)$ & 1.00 \\
\hline $24.3-26.4$ & $54(28)$ & $77(23)$ & 1.34 (0.89 to 2.14$)$ \\
\hline$\geqslant 26.5$ & $34(17)$ & $38(11)$ & 1.37 (1.05 to 1.79$)$ \\
\hline
\end{tabular}

Psychosocial conditions

Amount of work of sedentary nature(\%)

\begin{tabular}{lccc}
\hline$\leqslant 24$ & $70(36)$ & $125(38)$ & 1.00 \\
\hline $25-50$ & $41(21)$ & $67(20)$ & $1.03(0.60$ to 1.75$)$ \\
\hline $51-75$ & $36(18)$ & $77(23)$ & $0.77(0.45$ to 1.32$)$ \\
\hline$\geqslant 76$ & $48(25)$ & $62(19)$ & $1.27(0.75$ to 2.14$)$ \\
\hline Burnout index: & & \\
\hline Normal & $143(73)$ & $253(76)$ & 1.00 \\
\hline Borderline & $41(21)$ & $61(18)$ & $1.26(0.80$ to 1.97$)$ \\
\hline Burnout & $11(6)$ & $17(5)$ & $1.31(0.59$ to 2.90$)$
\end{tabular}

${ }^{*}$ Adjusted for age and occupation categories by conditional logistic regression.

†Occupation categories classified in 1990 Japanese census.

NA=Not applicable.

Table 2 Mean daily working hours of 195 Japanese men with acute myocardial infarction and 331 controls matched for age and occupation during the two months before infarction and in the months with the shortest and longest mean working hours in the year before infarction, and changes in mean daily working hours between each pair of months

\begin{tabular}{lrrr} 
& \multicolumn{2}{c}{ Mean (SE) working hours } & \\
\cline { 2 - 3 } & $\begin{array}{c}\text { Cases } \\
(\mathbf{n = 1 9 5 )}\end{array}$ & $\begin{array}{c}\text { Controls } \\
(\mathbf{n = 3 3 1 )}\end{array}$ & P value \\
\hline Mean daily working hours during a month* & & & \\
\hline A: Last month before infarction & $9.13(0.22)$ & $9.24(0.21)$ & 0.53 \\
\hline B: Month before last & $8.95(0.23)$ & $9.27(0.21)$ & 0.084 \\
\hline C: Month with shortest mean working hours & $7.45(0.21)$ & $8.17(0.19)$ & 0.0001 \\
\hline D: Month with longest mean working hours & $10.03(0.28)$ & $10.26(0.26)$ & 0.31 \\
\hline Change in mean daily working hours & & & \\
\hline A-B & $0.18(0.11)$ & $-0.03(0.10)$ & 0.018 \\
\hline A-C & $1.68(0.18)$ & $1.08(0.17)$ & 0.0001 \\
\hline A-D & $-0.90(0.20)$ & $-1.02(0.19)$ & 0.48 \\
\hline D-C & $2.58(0.26)$ & $2.09(0.25)$ & 0.022 \\
\hline
\end{tabular}

${ }^{*}$ Adjusted for age and occupation categories by using analysis of covariance.

cial conditions did not appreciably change these associations (table 3 ).

For the month with the shortest mean daily working hours, a short working day ( $\leqslant 6$ hours) was associated with an increased risk of infarction compared with working $>6-8$ hours (odds ratio 2.71 (1.60 to 4.60)). Adjustment for established and 
Table 3 Categorisation of working hours of 195 Japanese men with acute myocardial infarction and 331 controls matched for age and occupation, and odds ratios for infarction in relation to working hours

\begin{tabular}{|c|c|c|c|c|}
\hline \multirow[b]{2}{*}{$\begin{array}{l}\text { Mean daily working } \\
\text { hours }\end{array}$} & \multicolumn{2}{|c|}{ No $(\%)$ of subjects } & \multicolumn{2}{|c|}{ Odds ratio $(95 \% \mathrm{Cl})$} \\
\hline & $\begin{array}{l}\text { Cases } \\
(\mathrm{n}=195)\end{array}$ & $\begin{array}{l}\text { Controls } \\
(\mathrm{n}=331)\end{array}$ & Crude $^{*}$ & Multiple logistic \\
\hline \multicolumn{5}{|c|}{ In last month before infarction } \\
\hline$\leqslant 7.00$ & $45(23)$ & $32(10)$ & 3.07 (1.77 to 5.32$)$ & $2.83(1.52$ to 5.28$)$ \\
\hline $7.01-9.00$ & $80(41)$ & $182(55)$ & 1.00 & 1.00 \\
\hline $9.01-11.00$ & $46(24)$ & $96(29)$ & $1.06(0.68$ to 1.67$)$ & $0.96(0.58$ to 1.60$)$ \\
\hline$\geqslant 11.01$ & $24(12)$ & $21(6)$ & 2.44 (1.26 to 4.73$)$ & 2.94 (1.39 to 6.25$)$ \\
\hline \multicolumn{5}{|c|}{ In month with shortest mean working hours } \\
\hline$\leqslant 6.00$ & $46(24)$ & $31(9)$ & $2.71(1.60$ to 4.60$)$ & 2.59 (1.44 to 4.69$)$ \\
\hline $6.01-8.00$ & $96(49)$ & $195(59)$ & 1.00 & 1.00 \\
\hline $8.01-9.00$ & $32(16)$ & $59(18)$ & $1.08(0.65$ to 1.81$)$ & $1.03(0.59$ to 1.83$)$ \\
\hline$\geqslant 9.01$ & $21(11)$ & $46(14)$ & $0.89(0.49$ to 1.61$)$ & 0.93 (0.48 to 1.78$)$ \\
\hline \multicolumn{5}{|c|}{ Increase from month with shortest hours to month before infarction } \\
\hline$\leqslant 1.00$ & $121(62)$ & $244(74)$ & 1.00 & 1.00 \\
\hline $1.01-2.00$ & $30(15)$ & $50(15)$ & 1.28 (0.77 to 2.13$)$ & $1.33(0.75$ to 2.37$)$ \\
\hline $2.01-3.00$ & $18(9)$ & $17(5)$ & 2.24 (1.11 to 4.55$)$ & $2.38(1.08$ to 5.26$)$ \\
\hline$\geqslant 3.01$ & $26(13)$ & $20(6)$ & $2.53(1.34$ to 4.77$)$ & 2.49 (1.24 to 4.99$)$ \\
\hline
\end{tabular}

${ }^{*}$ Adjusted for age and occupation categories classified in 1990 Japanese census.

$\dagger$ †djusted for age, occupation category, hypertension, hypercholesterolaemia, diabetes, body mass index smoking habits, proportion of sedentary work, and burnout index.



Odds ratios (adjusted for age and occupation) for acute myocardial infarction among Japanese men by mean daily working hours during the month before infarction and change in mean daily working hours between the month with the shortest working hours and the month before the event

\section{Discussion}

This study is the first we know of to establish a relation between the mean working hours of employees and their risk of acute myocardial infarction, although we limited our data to non-fatal infarction. The risk of infarction was increased not only by unusually long working hours but also by shorter than average hours. Thus, a U shaped relation existed between mean working hours and risk of acute myocardial infarction. Because of this non-linearity, the mean working hours of the patient group was not different from that of the control group. There was also a trend for the risk of infarction to increase with greater increases in mean working hours from the month with the shortest mean working hours to the month before infarction.

\section{Explanations of results}

A possible biological explanation for long working hours eliciting an acute myocardial infarction might be changes in the activity of the autonomic nervous system. Work induced tension that increases sympathetic nerve activity increases blood pressure. Blood pressure is increased in both normotensive and hypertensive subjects while working - the longer the working hours, the higher the daily mean blood pressure. ${ }^{22}{ }^{23} \mathrm{In}$ addition, reduced activity of the parasympathetic nervous system increases the risk of coronary heart disease. ${ }^{24}{ }^{25}$ It has been suggested that parasympathetic nerve activity is decreased by weak stressors that do not increase sympathetic nerve activity. ${ }^{26}$ Even if the stressors encountered while working are weak, coronary risk could be increased by attenuated vagal tone. Recent epidemiological investigations of variations in heart rate have revealed a relation between increased sympathetic tone and long commuting time or extensive overtime. ${ }^{27}$ Smoking increases sympathetic nerve activity and decreases parasympathetic nerve activity. ${ }^{28}{ }^{29}$ The percentage of Japanese men who smoke is as high as 54\%. ${ }^{7}$ For non-smokers and former smokers, environmental smoke at the workplace might contribute to an increased risk of myocardial infarction. $^{30} 31$

Short mean working hours before the onset of myocardial infarction might indicate the presence of a premorbid condition, including preclinical ischaemic heart diseases. The increased risk of acute myocardial infarction in one man with short mean working hours was partially explained by established biomedical risk factors. However, mean working hours might also be shortened by unemployment, and Morris suggested that losing employment increases the risk of myocardial infarction. ${ }^{32}$ If this relation between unemployment and myocardial infarction is valid, then short mean working hours might not have been a marker of a premorbid condition but rather a causal factor in some cases. Too few working hours might lead to deterioration in lifestyle.

The risk of infarction increased with greater increases in mean working hours from the month with the shortest mean working hours to the month before infarction. Changes in mean working hours could affect the circadian rhythm of autonomic nerve activity, and failure of the autonomic nervous system to adapt adequately to such a change might be associated with increased risk of myocardial infarction. Our results ratios adjusted for age and occupation, $\mathrm{P}=0.002$ for multiple logistic odds ratios). 
show that the increase in mean working hours within the year preceding acute myocardial infarction contributed significantly to acute myocardial infarction. Previous studies of working hours have focused on rapid increases in hours over a short time. Our results indicate the necessity to pay attention to long term changes in working hours.

\section{Strengths and limitations of study}

Working conditions change according to employees' sex, age, and occupation. We matched these variables between patient and control groups. Therefore, there is little likelihood that considerable biases about working arrangements exist between them. Because recalling working hours by month was largely based on objective tables of salary details, recall bias should not be a problem in our study.

However, the recall bias between patients and controls is difficult to assess. It is possible that, after an acute myocardial infarction, a patient may negatively misinterpret his memories of his state of mind before the infarction. On the other hand, negative feelings may actually have been induced before a myocardial infarction. We found no significant differences between patient and control groups in psychosocial variables (such as burnout index and proportion of work of a sedentary nature) other than working hours. Therefore, it is unlikely that a psychological bias was responsible for our findings. Selection bias is also an improbable explanation for our results. Control subjects were matched with case subjects with respect to occupation and were recruited from many facilities so as not to represent a biased population. Our analyses adjusted for established and occupational risk factors for myocardial infarction. Residual confounding factors leading away from the null hypothesis are unlikely given the direction of the change in the odds ratio estimated with first univariate and then multivariate analyses.

In our subjects there was a considerable preponderance of managers and officials relative to manual workers. Of our patient group, 51\% were managers and officials and $12 \%$ were manual workers, whereas the percentages among employed people aged 50-59 years in Japan as a whole are $11 \%$ and $38 \%$ respectively (Japanese national census, 1990). There may be two possible reasons for this phenomenon. The first is that the populations that used the hospitals from which the patients in this study were recruited were biased in socioeconomic status. The second is that there were more patients in the class of managers and officials than in the class of manual workers. The second consideration has not been proved but has been hypothesised in Japan, although it differs from the results of the Whitehall II study. ${ }^{15}$ A comparative study between Britain and Japan is in progress.

\section{Conclusions}

We conclude that there was a $\mathrm{U}$ shaped relation between the mean monthly working hours of our subjects and their risk of acute myocardial infarction. In addition, there seemed to be a trend for the risk of acute myocardial infarction to increase with greater increases in working hours. Further study is necessary to clarify the mechanism for the $\mathrm{U}$ shaped association
Key messages

- It is suspected that extremely long working hours increase the risk of sudden death from too much occupational stress

- Few medical studies, however, have examined whether long working hours and a change in working hours influence the risk of acute myocardial infarction

- In a case-control study we found a U shaped association between mean monthly working hours and the risk of acute myocardial infarction

- In addition, there seemed to be a trend for the risk of acute myocardial infarction to increase with greater increases in working hours

- Further study is necessary to clarify the mechanism for the $\mathrm{U}$ shaped association and its influence on the low morbidity and mortality from acute myocardial infarction in Japan

and its influence on the low morbidity and mortality from acute myocardial infarction in Japan.

We thank Professor Kazunori Kodama and Former President Itsuzo Shigematsu (Radiation Effects Research Foundation) for their useful comments.

Contributors: SS, SK, and Director Tsutomu Takata (Occupational Health Service Center, Japan Industrial Safety and Health Association, Tokyo) initiated and coordinated the formulation of the primary study hypothesis. SS and SK discussed core ideas and participated in protocol design, data collection, analysis, and writing the manuscript. Dr Kazuo Haze (Osaka City General Hospital, Osaka), Dr Akira Seki (Toranomon Hospital, Tokyo), Dr Shigeki Koda (Kochi Medical School, Kochi), Dr Masao Ishizaki (Kanazawa Medical University, Ishikawa), Dr Yoshihiro Nishimoto (Central Health Supervision Office, East Japan Railway Company, Tokyo), Dr Kazunori Kayaba (Jichi Medical School, Tochigi), and Professor Katsuo Kanmatsuse (School of Medicine, Nihon University, Tokyo) all participated in protocol design and data collection. SS and SK are guarantors for the paper.

Funding: The study was supported by grants from the Japanese Ministry of Labour.

Conflict of interest: None.

1 Japanese Ministry of Labour. Year book of labour statistics 1995. Tokyo: Institute of Labour Administration, 1997

2 Uehata T. Long working hours and occupational stress-related cardiovascular attacks among middle-aged workers in Japan. J Hum Ergol (Tokyo) 1991;20:147-53.

3 Robertson TL, Kato H, Rhoads GG, Kagan A, Marmot M, Syme SL, et al. Epidemiologic studies of coronary heart disease and stroke in Japanese men living in Japan, Hawaii and California. Incidence of myocardial infarction and death from coronary heart disease. Am J Cardiol 1977;39:239-43.

4 Baba S, Ozawa H, Sakai Y, Terao A, Konishi M, Tatara K. Heart disease deaths in a Japanese urban area evaluated by clinical and police records. Circulation 1994;89:109-15.

5 Naruse Y, Nakagawa H, Yamagami T, Sokejima S, Morikawa Y, Nishijo M, et al. Ischaemic heart disease deaths in a Japanese rural area evaluated by clinical records. J Epidemiol 1997;7:71-6.

6 Marmot MG, Syme L. Acculturation and coronary heart disease in Japanese-Americans. Am J Epidemiol 1976;104:225-47.

7 Japanese Ministry of Health and Welfare. National survey of circulatory disorders 1990. Osaka: Japan Cardiovascular Research Foundation, 1993.

8 Ueshima $\mathrm{H}$. Changes in dietary habits, cardiovascular risk factors and mortality in Japan. Acta Cardiol 1990;45:311-27.

9 Okayama A, Ueshima H, Marmot MG, Nakamura M, Kita Y, Yamakawa $M$. Changes in total serum cholesterol and other risk factors for cardiovascular disease in Japan 1980-1989. Int J Epidemiol 1993;22:1038-47.

10 Hammar N, Alfredsson L, Theorell T. Job characteristics and the incidence of myocardial infarction. Int J Epidemiol 1994;23:277-84.

11 Reed DM, LaCroix AZ, Karasek RA, Miller D, MacLean CA. Occupational strain and the incidence of coronary heart disease. Am J Epidemiol 1989;129:495-502. 
12 Marmot MG, Smith GD, Stansfeld S, Patel C, North F, Head J, et al. Health inequalities among British civil servants: the Whitehall II study. Lancet 1991;337:1387-93.

13 Marmot MG, Bosma H, Hemingway H, Brunner E, Stansfeld S. Contribution of job control and other risk factors to social variations in coronary heart disease incidence. Lancet 1997·350.235-9.

14 Pais P, Pogue J, Gerstein H, Zachariah E, Savitha D, Jayprakash S, et al. Risk factors for acute myocardial infarction in Indians: a case-control study. Lancet 1996;348:358-63.

15 Japanese Ministry of Health and Welfare. Special report of vital statistics in 1990. Occupational and industrial aspects. Tokyo: Health and Welfare Statistics Association, 1994.

16 Alfredsson L, Hammar N, Hogstedt C. Incidence of myocardial infarction and mortality from specific causes among bus drivers in Sweden. Int J and mortity from specific

17 Stender M, Hense HW, Doring A, Keil U. Physical activity at work and cardiovascular disease risk: results from the MONICA Augsburg study. Int J Epidemiol 1993;22:644-50.

18 Appels A, Schouten E. Burnout as a risk factor for coronary heart disease. Behav Med 1991;17:53-9.

19 Tuomilehto J, Salonen JT, Marti B, Jalkanen L, Puska P, Nissinen A, et al. Body weight and risk of myocardial infarction and death in the adult population of eastern Finland. BMJ 1987;295:623-7.

20 Hosmer DW, Lemeshow S. Applied logistic regression. New York: John Wiley and Sons, 1989.

21 SAS Institute. Conditional logistic regression for m:n matching. In: SAS/ STAT software:changes and enhancements through release 6.11. Cary, NC: SAS Institute, 1996.

22 Hayashi T, Kobayashi Y, Yamaoka K, Yano E. Effect of overtime work on 24-hour ambulatory blood pressure. J Occup Environ Med 1996;38: 1007-11.
23 Pieper C, Warren K, Pickering TG. A comparison of ambulatory blood pressure and heart rate at home and work on work and non-work days. $J$ Hypertens 1993;11:177-83.

24 Hayano J, Sakakibara Y, Yamada M, Ohte N, Fujinami T, Yokoyama K, et al. Decreased magnitude of heart rate spectral components in coronary artery disease. Its relation to angiographic severity. Circulation 1990;81:1217-24.

25 Hayano J, Yamada A, Mukai S, Sakakibara Y, Yamada M. Severity of coronary atherosclerosis correlates with the respiratory component of heart rate variability. Am Heart J 1991;121:1070-9.

26 Mukai S, Hayano J. Heart rate and blood pressure variabilities during graded head-up tilt. J Appl Physiol 1995;78:212-6.

27 Kageyama T, Nishikido N, Kobayashi T, Kurokawa Y, Kabuto M. Commuting, overtime, and cardiac autonomic activity in Tokyo. Lancet 1997;350:639.

28 Christensen NJ, Jensen EW. Sympathoadrenal activity and psychosocial stress. The significance of aging, long-term smoking, and stress models. Ann N Y Acad Sci 1995;771:640-7.

29 Havano J, Yamada M, Sakakibara Y, Fujinami T, Yokovama K, Watanabe Y, et al. Short- and long-term effects of cigarette smoking on heart rate variability. Am J Cardiol 1990;65:84-8.

30 Muscat JE, Wynder EL. Exposure to environmental tobacco smoke and the risk of heart attack. Int J Epidemiol 1995;24:715-9.

31 Hammond SK, Sorensen G, Youngstrom R, Ockene JK. Occupational exposure to environmental tobacco smoke. JAMA 1995;274:956-60.

32 Morris JK, Cook DG, Shaper AG. Loss of employment and mortality. BMJ 1994;308:1135-9.

(Accepted 8 June 1998)

\title{
As seen on TV: observational study of cardiopulmonary resuscitation in British television medical dramas
}

\author{
P N Gordon, S Williamson, P G Lawler
}

South Cleveland
Hospital,
Middlesbrough
TS4 3BW
P N Gordon,
senior house officer in
intensive care
S Williamson,
senior registrar in
anaesthetics
P G Lawler,
consultant in
intensive care
Correspondence to:
Dr P N Gordon,
Department of
Obstetrics and
Gynaecology, South
Cleveland Hospital,
Middlesbrough
TS4 3BW
patrickg@
globalnet.co.uk

BMJ 1998;317:780-3

\begin{abstract}
Objective: To determine the frequency and accuracy with which cardiopulmonary resuscitation is portrayed in British television medical dramas. Design: Observational study.

Subjects: 64 episodes of three major British television medical dramas: Casualty, Cardiac Arrest, and Medics.

Main outcome measures: Frequency of cardiopulmonary resuscitation shown on television; age, sex, and diagnosis of the patients undergoing resuscitation; rate of survival through resuscitation. Results: Overall 52 patients had a cardiorespiratory arrest on screen and 3 had a respiratory arrest alone, all the arrests occurring in 40 of the 64 episodes. Of the 52 patients having cardiorespiratory arrest, 32 $(62 \%)$ underwent an attempt at cardiopulmonary resuscitation; 8 attempts were successful. All 3 of the patients having respiratory arrests alone received ventilatory support and survived. On $48 \%$ of occasions, victims of cardiac arrest seemed to be less than 35 years old.

Conclusions: Cardiorespiratory resuscitation is often depicted in British television medical dramas. Patients portrayed receiving resuscitation are likely to be in a younger age group than in real life. Though the reasons for resuscitation are more varied and more often associated with trauma than in reality, the overall success rate is nevertheless realistic. Widespread overoptimism of patients for survival after resuscitation cannot necessarily be blamed on British television medical dramas.
\end{abstract}

\section{Introduction}

Since Kouwenhoven's original description of modern cardiopulmonary resuscitation $^{1}$ and the obvious early successes of the technique, ${ }^{2}$ resuscitation has become increasingly commonplace in hospitals and the community. The advent of prompt resuscitation and the ready availability of intensive care has produced moral dilemmas about the appropriateness of resuscitation in some patients and in some situations. Until recently it has been common hospital practice for most end of life decisions that concern resuscitation or the institution of intensive care in hospital patients to be taken by the clinicians in charge of the individual's care. ${ }^{3}$ In recent years there has been a move towards more open discussion about end of life decisions with patients and their families, often in advance preparation for critical illness and with a view to making living wills or advance directives.

It has been recognised that patients, their relatives, and the doctors and nurses responsible for their care often have an unrealistically optimistic impression of the effectiveness of resuscitation. ${ }^{5-7}$ Furthermore it has been shown that patients' perception of the likelihood of success of resuscitation has a strong effect on their desire for resuscitation or intensive care in the event of their own critical illness. ${ }^{8}{ }^{9}$ The public's knowledge of complex medical issues such as resuscitation is becoming increasingly sophisticated, and the factors influencing this knowledge are many and varied. Information may come from personal experience or from external sources, including life support training programmes, newspaper and magazine journalism, and television 